\title{
Poéticas do Teatro do Oprimido na Saúde Mental
}

Emanuella Cajado Joca. Universidade Federal do Rio Grande do Norte

Maria Teresa Nobre. Universidade Federal do Rio Grande do Norte

Maria Rocineide Ferreira da Silva. Universidade Estadual do Ceará

\section{Resumo}

O Teatro do Oprimido (TO) é uma abordagem artístico-política e sua intersecção com o campo da saúde mental é objeto deste artigo. Apresentamos uma pesquisa-intervenção inspirada na Análise Institucional, que propôs uma construção coletiva de conhecimento a partir da análise do diário de campo de facilitação de um Grupo de Teatro do Oprimido em um Centro de Atenção Psicossocial. Desse momento, foram elencados quatro temas/analisadores: compreensões sobre o TO na Saúde Mental; proposição teórico-prática do TO; trabalho na saúde mental; a experiência com a Oficina de Conversação Coletiva. Evidenciou-se que o TO problematiza relações assimétricas e subjugadoras, colocando em pauta questões como doença, tratamento e cura. Por fim, ressalta-se a importância do diálogo coletivo acerca das práticas de atenção em saúde mental que estão em processo de construção no Brasil, fortalecendo desse modo o cuidado e estimulando o protagonismo de trabalhadores e usuários.

Palavras-chave: Teatro do Oprimido; saúde mental; pesquisa-intervenção.

\begin{abstract}
Poetics of the Theatre of the Oppressed in mental health. The Theater of the Oppressed (TO) is an artistic-political approach and its intersection with the field of mental health is the subject of this article. We present an intervention research anchored in Qualitative Epistemology, which proposed a collective construction of knowledge from the analysis of the field diary of facilitation of a Group of Theater of the Oppressed in a Center of Psychosocial Attention. From that moment, four categories were listed: understandings about TO in Mental Health; theoretical-practical proposition of TO; work in mental health; the experience with the Workshop of Collective Conversation. It was evidenced that the TO problematizes asymmetrical and subjugating relations, putting in question subjects like disease, treatment and cure. Finally, the importance of collective dialogue about mental health care practices that are under construction in Brazil is reinforced, thus strengthening care and stimulating the protagonism of workers and users.
\end{abstract}

Keywords: Theater of the Oppressed; mental health; intervention-research.

\section{Resumen}

Poética del Teatro del Oprimido en salud mental. El Teatro del Oprimido (TO) es un enfoque artístico-político y su intersección con el campo de la salud mental es objeto de este artículo. Presentamos una investigación-intervención anclada en la Epistemología Cualitativa, que propuso una construcción colectiva de conocimiento a partir del análisis del diario de campo de facilitación de un Grupo de Teatro del Oprimido en un Centro de Atención Psicosocial. De ese momento, fueron enumeradas cuatro categorías: comprensiones sobre el TO en la Salud Mental; proposición teórico-práctica del TO; trabajo en la salud mental; la experiencia con el taller de Conversación Colectiva. Se evidenció que el TO problematiza relaciones asimétricas y subyugadoras, planteando en pauta cuestiones como enfermedad, tratamiento y curación. Por último, se resalta la importancia del diálogo colectivo acerca de las prácticas de atención en salud mental que están en proceso de construcción en Brasil, fortaleciendo así el cuidado y estimulando el protagonismo de trabajadores y usuarios.

Palabras clave: Teatro del Oprimido; salud mental; investigación-intervención. 
O Teatro do Oprimido na saúde mental é o foco deste artigo. Esta metodologia teatral foi desenvolvida pelo teatrólogo Augusto Boal (1931-2009), brasileiro com naturalidade carioca que trabalhou com diversos grupos, utilizando o diálogo cênico como forma de problematizar as relações sociais opressivas. O objetivo do Teatro do Oprimido é a desmecanização dos sujeitos e o estímulo ao protagonismo social por meio do acesso à produção artística, através de jogos e exercícios teatrais buscando promover a criação de si e do mundo.

O campo da saúde mental no Brasil passou por processos de muitas transformações ao longo das três últimas décadas. Entre os anos 1980 e 2000 a reforma psiquiátrica lançou suas bases a partir da contestação ao modelo manicomial e asilar, a ser substituído por outros espaços de cuidado e atenção à saúde mental, de base territorial e comunitária, estimulando-se o tratamento em liberdade. A reestruturação da assistência psiquiátrica sobre a qual dispõe a Lei 10.216, de 6 de abril de 2001 é uma conquista das lutas de trabalhadores da saúde mental, usuários, familiares e sociedade civil, iniciada no final dos anos 1970, que além de rever criticamente o papel do hospital psiquiátrico e da psiquiatria como saber hegemônico e centralizador no cuidado à saúde mental, propõe a garantia de direitos humanos dos usuários e seus familiares. Essas mudanças inserem-se no bojo da Reforma Sanitária que teve seu marco na $8^{\text {a }}$ Conferência Nacional de Saúde (1986) e se consolidou com a Constituição Federativa do Brasil (1988) e com a Lei Orgânica da Saúde (1990), que instituíram no Brasil princípios e diretrizes de uma saúde pública como direito de todos e dever do Estado, através do Sistema Único de Saúde. Deste modo, o acesso a um cuidado humanizado em saúde mental só é possível se forem garantidos os princípios de universalidade, integralidade e equidade em saúde, preconizados pelo SUS.

Amarante (2007), Amarante e Costa (2012), Costa-Rosa, Luzio e Yasuí (2003) apontaram o paradigma psicossocial como alternativa de atenção ao modelo asilar, baseado no paradigma biomédico e visto como ineficiente e degradante. A Atenção Psicossocial, desse modo, tem sustentado ações que possuem uma perspectiva da autonomia dos sujeitos e protagonismo, cunhando o desenvolvimento de um olhar plural em suas diversas dimensões teórico-práticas, político-ideológicas e éticas. São equipamentos da rede de atenção à saúde mental: os Centros de Atenção Psicossocial (CAPS), leitos psiquiátricos em hospitais gerais, oficinas terapêuticas, residências terapêuticas, centros de convivência, destacando-se as singularidades regionais no processo de sua implantação.

Entretanto, este ainda é um campo em construção no Brasil, definido por Lancetti e Amarante (2015) como área de conhecimento e de atuação complexos, com atravessamentos de ordem ideológica, política, social e cultural.

Para se constituir em uma alternativa de cuidado em saúde mental o modo psicossocial precisa se fortalecer em quatro campos: teórico-assistencial/epistemológica (mudar a fundamentação das práticas); técnico-assistencial (mudança nas práticas); o jurídico-político (estruturação legal) e o sociocultural (transformações nas concepções sociais acerca da loucura). No teórico-assistencial o foco deve ser o sujeito como ator ativo do seu processo terapêutico e a noção seria de existência-sofrimento ao invés de doença-cura; no campo técnico-assistencial o foco recai sobre o sujeito de direitos em equipamentos para o cuidado em liberdade; no jurídico-político a centralidade é a luta por estruturação de leis, novas atuações e garantia/conquista de direitos e no sociocultural as práticas sociais que visam transformar o imaginário de grupos (Costa-Rosa et al., 2003).

Na Política Nacional de Saúde Mental se expandem os Centros de Atenção Psicossocial (CAPS) e nesse processo o Ministério da Saúde $(2007,2011)$ apoiou o Centro de Teatro do Oprimido do Rio de Janeiro (CTO-RJ) na formação dos trabalhadores da saúde nesta abordagem teatral. Essa experiência foi registrada pelo CTO-RJ, na Revista Metaxis (2010).

Portanto, a imagem tema deste artigo é o diálogo entre o método artístico-político sistematizado por Boal e o campo psicossocial em processo de construção no Brasil. Para tanto, apresentamos uma experiência de pesquisa-intervenção no campo das políticas de saúde mental. Colocamos em análise processos de trabalho, buscando compreender práticas de cuidado com foco em intervenções com Teatro do Oprimido. Construindo conhecimento acerca dessa intersecção e examinando de forma coletiva os significados da vivência com Teatro do Oprimido, aqui considerada como uma práxis problematizadora de estigmas, normatizações, discriminações e violências, em consonância com a Reforma Psiquiátrica Brasileira, a Luta Antimanicomial e a Saúde Coletiva.

\section{O Teatro do Oprimido}

Foi entre 1950 e 1960 que Augusto Boal junto a outros artistas pensaram e propuseram outras 
possibilidades para a arte teatral brasileira (Magaldi, 1984). Nesse período, Boal era diretor do Teatro de Arena de São Paulo e buscava um teatro brasileiro que falasse acerca da realidade do país e de sua dinâmica social.

Augusto Boal estava iniciando o que posteriormente chamará de Teatro do Oprimido (TO), uma metodologia teatral enraizada em fundamentos filosóficos, políticos, econômicos, históricos e sociais, estruturado em jogos e exercícios demecanizadores e estimuladores da produção da palavra, imagem e som. Essas constituem a sustentação das vertentes do Teatro do Oprimido desenvolvidas ao longo de toda a trajetória do autor. Boal (2019) sistematizou a metodologia do TO em quatro etapas: 1- conhecimento do corpo; 2- tornar o corpo expressivo; 3- o teatro como linguagem; 4- teatro como discurso. Amadurecerá estas etapas em toda a sua obra e para tanto usa a imagem da árvore como analogia para seu método (Figura 1).

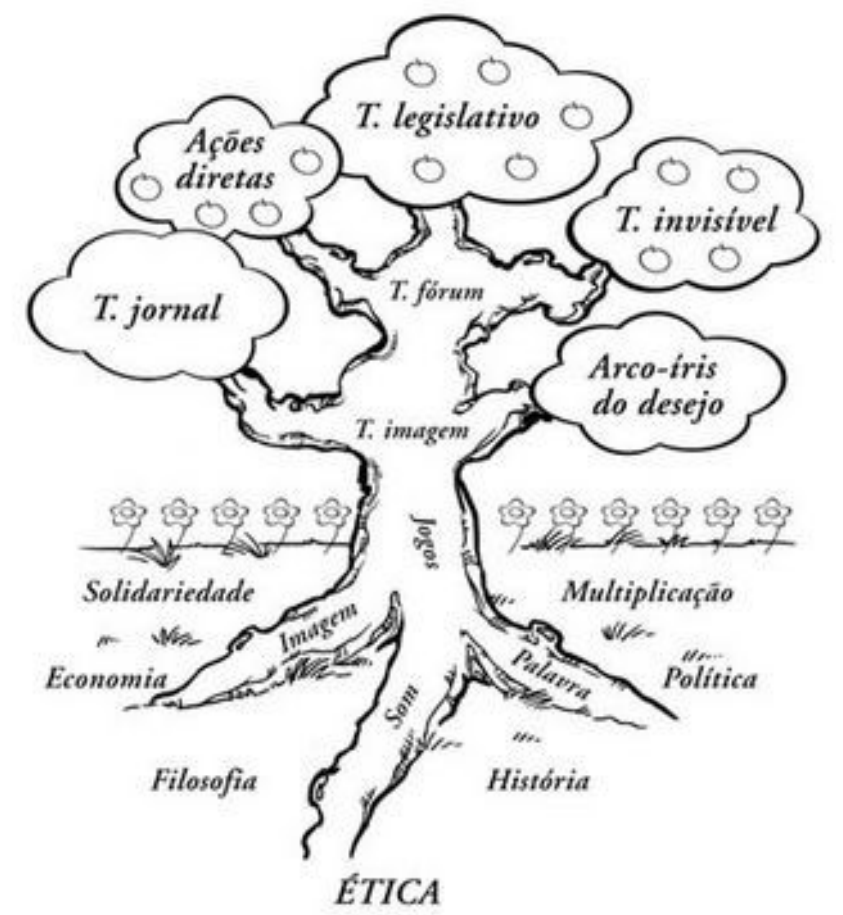

Figura 1. Árvore do Teatro do Oprimido. Fonte: Boal (2009a).

A sustentação da Árvore do Teatro do Oprimido está baseada na filosofia crítica, história, economia, multiplicação, política, solidariedade e ética (Boal, 2009a). Estas bases nutrem a copa pela palavra, imagem e som, canais de dominação e de libertação. É o estímulo ao sujeito da fala, que pela expressão artística veicula suas ideias e propõe questionamentos acerca das opressões que vivencia. Os jogos e exercícios localizados no caule da árvore são como sustentação e canais de ligação. Favorecem as duas primeiras etapas do método que investigam os limites e estimulam as possibilidades do corpo, base da produção expressiva do sujeito ativo.

Boal (1998) utiliza a denominação joguexercícios para intitular a sistematização de jogos e exercícios escoIhidos em função dos objetivos do Teatro do Oprimido, que busca desenvolver nas pessoas a capacidade de se expressar através do teatro. Os exercícios visam estimular o conhecimento do corpo, seus mecanismos, atrofias, capacidades de recuperação e reestruturação.

O exercício é uma reflexão física de si mesmo." (p. 87) e os jogos seriam estimuladores da expressividade do corpo, do diálogo e da extroversão. Mas essa divisão seria apenas didática e, portanto, "os jogos e exercícios [...] são antes de tudo joguexercícios, havendo muito de exercício nos jogos e vice-versa (p. 87).

Boal (1998) compreende que o ser humano é uma unidade, entre aparelho físico, psíquico e os cinco sentidos. Desenvolve cinco categorias de joguexercícios, que buscam a des-especialização ou desmecanização humana. São Elas: 1- Sentir tudo que se toca; 2- Escutar tudo que se ouve; 3- Ativar os vários sentidos; 4- Ver tudo que se olha; e 5- A memória dos sentidos.

Posteriormente aos joguexercícios, encontram-se na Árvore do Teatro do Oprimido as chamadas vertentes. As duas colocadas por Boal (2009) ainda no caule não foram as primeiras criadas, mas as que têm maior amplitude entre as vertentes desenvolvidas. O Teatro Imagem trabalha a polissemia das imagens através de exercícios de improvisação e representação. O Teatro Fórum é a vertente mais difundida da abordagem boaleana, no qual um grupo de atores e/ou não-atores monta uma cena vivida por um dos participantes, na qual o conflito principal é o foco, em que existe um opressor e um oprimido que disputam. Porém, o oprimido buscando conseguir seu objetivo vivencia limites e diante dessa cena os espectatores ${ }^{1}$ são convidados a representar o oprimido e propor novas alternativas para conseguir seu objetivo.

Crescendo nesta copa está o Teatro Jornal que problematiza cenicamente as notícias veiculadas pelos jornais e consiste no primeiro modo desenvolvido por Boal ainda antes de ser preso e torturado pela ditadura civil-militar brasileira no final dos anos de 1960 e início de 1970. Segue com o Teatro Invisível, bem desenvolvido no exílio, primeiramente, na Argentina, mas também na Europa (Boal, 2000). 
O Arco-Íris do desejo (método terapêutico) é a proposição de um momento do trabalho de Boal (2002) com mais de 40 anos de experiência no Brasil e América Latina. Estava ainda no exílio e vivenciava a realidade europeia, questionando as opressões internalizadas. Já o Teatro Legislativo é uma experiência construída no Brasil após o retorno do exílio. É a partir do Teatro Fórum que se elabora debates para formulação de Leis que amparem as necessidades dos grupos sociais oprimidos. Finalmente, as Ações Diretas $e$ Continuadas, que são sempre o objetivo do Teatro do Oprimido, consistem na atuação social de luta, propiciadoras e estimuladoras do florescimento e da transformação social realizada por cidadãos ativos.

Todas essas proposições vão estimular a produção da Estética do Oprimido, que é a tomada do poder da palavra, da imagem e do som, historicamente canais de dominação das classes dominantes que perpetuam suas ideias por tais veículos. Nesse sentido, a Estética do Oprimido é na luta social, um instrumento de libertação. Consiste, também, na última escrita de Augusto Boal (2009b) publicada postumamente. $\mathrm{O}$ autor coloca o Teatro do Oprimido como uma metodologia da Estética do Oprimido que integra todas as artes que estão no teatro e são estimuladoras da expressão e empoderamento dos grupos oprimidos.

\section{Caminhos investigativos}

Este estudo caracteriza-se como pesquisa-intervenção e aproxima-se das elaborações de Lourau (2004, 2014), que junto com o movimento institucionalista, busca o que chamam de descentramento dos pressupostos que estariam no centro da ciência positivista (Lourau, 2004), em particular a neutralidade tão cara ao método científico quando ressaltam a análise da implicação do pesquisador como uma das ferramentas e ponto de partida da Análise Institucional.

A pesquisa-intervenção privilegia a pesquisa em situação e busca romper as dicotomias entre sujeito-objeto, considerando que o pesquisador é parte do seu campo de intervenção e de análise. O processo de pesquisa consiste num exercício de desnaturalizar o que está instituído e potencializar mudanças no campo investigado. Neste sentido, o trabalho de análise coletiva de implicação (Lourau, 2004), além de romper com a ideia de neutralidade na pesquisa, coloca em discussão as relações de poder-saber das instituições que atravessam a experiência, como a política, a saúde mental e o saber acadêmico, no caso desta experiência.
De forma geral a Análise Institucional busca colocar em análise e/ou movimento as relações de forças que sustentam as instituições. Esta para o autor é definida como: "Uma norma universal, ou considerada como tal, quer se trate do casamento ou da educação, quer da medicina, do trabalho assalariado, do lucro, do crédito." (Lourau, 2014, p. 15). As instituições são normas em processo dialético entre as forças instituintes e instituídas das relações sociais. Desde suas origens, a corrente institucionalista pôs ênfase na relação antagonista entre instituinte e o instituído e nos processos ativos da institucionalização. A alienação social significa a autonomização institucional, a dominação do instituído fundada no esquecimento de suas origens, na naturalização das instituições. Produzidas pela história, elas acabam por aparecer como fixas e eternas, como algo dado, condição necessária e trans-histórica da vida das sociedades. (Lourau, 2004, p. 73).

É a análise dessas forças nas relações sociais que a Análise Institucional vai buscar. Lourau (1993, 2004, 2014) e Lapassade $(1989,1995)$ constituem todo um estudo no campo das instituições e de como essas se materializam em grupos e organizações. Esse trabalho de intervenções e análises, passando pela psicossociologia, psicanálise, marxismo, sociologia dos grupos, os leva a propor a Socioanálise.

Apesar de utilizar ferramentas da Análise Institucional a pesquisa-intervenção que discutimos neste artigo não se configura como uma intervenção institucionalista clássica. Inspira-se em um movimento como o relatado por Spagnol (2013), que também fez uso dos princípios operatórios da Al, buscando a produção de dispositivos de fala, de análise de práticas e que se focaliza no objeto de estudo.

A experiência foi realizada em um Centro de Atenção Psicossocial (CAPS) da cidade de Fortaleza. Com o trabalho desenvolvido junto a um Grupo de Teatro do Oprimido (GTO) neste serviço, essa investigação foi traçando um caminho de construção de inteligibilidade acerca do Teatro do Oprimido na Saúde Mental.

É oportuno explicitar a organização na Rede de Atenção Psicossocial (RAPS) que teve suas normas ratificadas na Portaria de Consolidação $n^{\circ} 3$, de 28 de setembro de 2017 do Ministério da Saúde. Conforme esta portaria, os CAPS são divididos em três modalidades (CAPS I, CAPS II e CAPS III) e se caracterizam por serviços de atendimento a adultos e crianças (CAPS i) com transtornos mentais graves e persistentes e com 
necessidades decorrentes do uso/abuso de crack, álcool e outras drogas (CAPS AD).

Os CAPS tipo I são indicados para municípios com população entre 20.000 e 70.000 habitantes, os de tipo II para municípios com população entre 70.000 e 200.000 habitantes, os de tipo III são os serviços com funcionamento 24 horas, incluindo clínica e acolhimento noturno e são indicados para população acima de 200.000 habitantes. A Portaria de $n^{\circ} 3.588$, de 21 de dezembro de 2017 instituiu uma nova modalidade de CAPS, o tipo IV para municípios com população acima de 500.000 habitantes e capitais estaduais. Essa modalidade foi criada apenas para Centros de Atenção Psicossocial de Álcool e outras drogas (CAPS AD) e está previsto para funcionamento 24 (vinte e quatro) horas, todos os dias e deve funcionar junto a cenas de uso de drogas.

$\mathrm{Na}$ cidade Fortaleza os CAPS estão organizados em tipo II e III, divididos em Gerais para adultos com transtornos mentais de forma geral, CAPSi para crianças e adolescentes e os específicos de álcool e outras drogas $(A D)$, exclusivos para pessoas com uso/abuso de substâncias psicoativas. O trabalho de pesquisa-intervenção aqui apresentado ocorreu com um Grupo de Teatro do Oprimido que funcionou em um CAPS Geral tipo II.

As vivências do Grupo de Teatro do Oprimido, que funcionaram em formato longitudinal e aberto durante oito meses com encontros semanais, constitui o cenário da pesquisa. O nome do grupo foi elaborado pelas pessoas participante como GTO Sociedade CAPS. O número de integrantes nunca foi fixo e tinha caráter aberto decorrente de um acordo construído coletivamente. No entanto, estiveram presentes por volta de 22 pessoas mais assiduamente. Cabe observar que os participantes tiveram tempos de inserção diferentes por conta da especificidade do grupo, que ao se caracterizar como uma pequena sociedade continha a premissa de estar sempre aberto, conforme encaminhado pelo grupo.

O trabalho foi dirigido pela primeira autora deste artigo como pesquisa de campo para elaboração da sua dissertação de mestrado e seguiu a Resolução N 466/12 do Conselho Nacional de Saúde (2012) que dispõe sobre pesquisas com seres humanos. O projeto foi apreciado pelo Comitê de Ética em Pesquisa da Universidade Estadual do Ceará (CEP/UECE) e aprovado com o número de parecer 1.978.556.

A experiência foi realizada com o apoio de alguns trabalhadores do serviço e durante o tempo de atividade do GTO Sociedade CAPS a pesquisadora realizou um relato do lugar de facilitadora de oficinas de Teatro do Oprimido.
Esse registro, que intitulamos Diário de Campo, constitui uma influência da pesquisa-intervenção proposta por Lourau (1993) que estudou em profundidade os Diários de Campo de alguns pesquisadores e propôs esse meio não como algo mecânico a ser produzido diariamente, mas como um instrumento de reconstituição da história subjetiva do pesquisador e também como fonte de conhecimento da pesquisa, sendo ferramenta para a análise da implicação do analista e para restituição da intervenção aos coletivos pesquisados, principalmente na socioanálise.

Nesta pesquisa, o Diário de Campo se constitui como objeto de análise de outros trabalhadores que estiveram ligados às atividades do Grupo de Teatro do Oprimido e que de modo colaborativo analisaram coletivamente a prática com o TO, a partir desse registro.

A pesquisa-intervenção objetivou fomentar a reflexão crítica acerca da prática profissional do trabaIhador da saúde, que em se tratando de saúde mental, configura-se como um modelo que almeja superar ou transformar um modo de atenção em saúde marcado por exclusão e práticas que retiram das pessoas seus direitos, inclusive de manifestar-se como sujeito. Nesse sentido, faz-se necessário que o trabalhador problematize cotidianamente suas ações e de forma coletiva perceba-se como ator do processo de construção de outros modos de cuidado, colocando em análise os modos de funcionamento institucional que atravessam suas práticas.

Portanto, os momentos investigativos na pesquisa buscaram a construção de inteligibilidade do tema abordado, sendo percorridas cinco etapas: Sistematização e análise do Diário de Campo de facilitação do GTO; Oficina de Conversação Coletiva com trabalhadores; Entrevistas individuais com participantes do GTO; e ainda uma Oficina de Restituição da Pesquisa. Essas duas últimas etapas não são discutidas neste artigo. Priorizamos um recorte com foco no Diário de Campo e na Oficina de Conversação Coletiva para que aprofundar aspectos relevantes da experiência aqui descrita.

Nesta pesquisa-intervenção o Diário de Campo foi transformado em um dispositivo de conversação com trabalhadores, que estiveram ligados às atividades do Teatro do Oprimido e que de modo colaborativo foram convidados a pensar coletivamente esta metodologia teatral em saúde mental. O Diário de Campo foi transcrito para meio digital, impresso e compartilhado com os pesquisadores-trabalhadores convidados para uma construção teórica conjunta. É oportuno dizer que, para efeitos deste artigo, o Diário de Campo foi resumido, focando um panorama geral. 


\section{Momentos investigativos: elaborando um dispositivo analítico}

O primeiro momento investigativo observado é o Diário de Campo da experiência de facilitar um Grupo de Teatro do Oprimido (GTO) Sociedade CAPS. As atividades deste GTO ocorreram de julho de 2015 até 18 de maio de 2016, quando no Theatro José de Alencar o grupo fez uma apresentação nas comemorações ao dia da Luta Antimanicomial. As proposições com a Estética do Oprimido envolveram artes plásticas, construção de textos em poesia, prosa, frases, músicas, bem como a declaração de si, técnicas propostas por Boal, (2009b).

Nos momentos iniciais foi priorizada a criação de vínculos para os (re)encontros. As incursões no Teatro do Oprimido eram precedidas de um alongamento corporal e percepção da respiração. Dessa maneira o grupo concentrava-se para estar junto e para a ação. Com essa introdução ao contexto grupal e investigativo propunham-se os joguexercícios.

Como discutido anteriormente, Boal (1998) define exercícios como movimento físico, muscular, respiratório, motor, vocal que ajude a quem os faz (re) conhecer seu corpo, seus músculos e nervos. Nesse sentido, o exercício é uma reflexão física sobre si mesmo. Os jogos colocam a expressividade dos corpos como emissores e receptores de mensagens.

É importante pontuar a especificidade do grupo estar sempre aberto. Essa questão abriu espaço para acolher, a qualquer momento, um novo integrante ou mesmo um curioso para ver como funcionava aquele grupo, onde se relatava haver muitos gritos, risadas e movimentos diferentes. Brincávamos e conversávamos, sendo o brincar às vezes questionado dentro e fora do grupo. A cristalização dos corpos estranha o lúdico, que é colocado como pertencente a um determinado momento do viver, empobrecendo os modos de estar no mundo.

Nesse processo, diversas indagações/questionamentos foram produzidos, tais como: a questão da cura das doenças que portavam, problematização sobre o término do tratamento naquele espaço e porque essa doença, mesmo com tantos remédios, não manifestava um processo de cura.

Em determinado encontro, realizou-se o compartilhar das histórias de opressão. Esse consiste em um momento do Teatro do Oprimido para a construção de uma questão cênica. Cada participante falou de uma experiência de opressão que o marcou e que ainda o incomodava. As histórias versaram sobre: a relação familiar opressora; experiência de ter uma orientação sexual discriminada socialmente; o ambiente escolar; rejeições; violência doméstica; internação involuntária. Foi um momento de expressões através da fala e muito rica de interações entre os participantes, durante as exposições. Desses relatos, a cada vez escolhemos inicialmente um para ensaiarmos formas de enfrentamentos.

A internação involuntária foi a primeira questão que todos decidiram discutir cenicamente. A partir da história de uma participante, que montou a cena, fizemos um fórum para discutir a situação. As pessoas observaram e se colocaram na posição de tentar alternativas. O sujeito em crise é enganado, levado ao hospital psiquiátrico e diante do médico fala que não deseja ser internado. Nesta cena houve muita discussão e reflexão, a problematização da doença mental e das suas formas de tratamento, aos quais muitos foram submetidos, tornando-se objetos "coisificados".

O ano estava terminando e o grupo desejava apresentar-se no festejo de Natal do CAPS. Montaram uma cena sobre crianças rejeitadas e pobres. Foi emocionante a relação com a plateia, que contava com demais usuários, familiares e trabalhadores do serviço. Apesar de não ter se caracterizado como Teatro-Fórum, o grupo fez o encaminhamento possível de acordo com aquilo que o caracterizava naquele momento.

A chegada de 2016 foi de desestabilização. Questões políticas de sucateamento dos serviços estavam se agravando, fato que pode ser observado no estudo de Nunes, Guimarães e Sampaio (2016). Os autores verificaram dificuldades no município para efetivar processos de cuidado conforme o modo da atenção psicossocial, principalmente, em decorrência do modelo de gestão, do financiamento, da qualificação das equipes e da precarização do trabalho. No entanto, lutávamos para montar um espetáculo de fórum. A falta de vale-transporte esvaziava o grupo e trazia muitos participantes esporádicos, dificultando o amadurecimento de ações.

Nesse contexto de esvaziamento, o GTO recebeu o convite para compor um grupo experimental. Integramos um coletivo junto a outros grupos de teatro da cidade para montar uma encenação da Paixão de Cristo, a partir da problematização da discriminação social e da diferença. Construímos a Amarga Ceia e nos apresentamos em praças da cidade com o tema de uma Paixão de Cristo entrecruzada pela história dos moradores 
de rua. Outra atividade foi realizada pelo grupo no Dia Mundial da Luta Antimanicomial (18 de maio), com apresentação no Theatro José de Alencar.

A segunda etapa do momento investigativo foi A oficina de conversação coletiva. Buscando a construção coletiva de conhecimento e a produção de espaços dialógicos, este momento convidou trabalhadores do serviço a serem pesquisadores acerca das práticas de cuidado com Teatro do Oprimido. Essa condição de protagonistas na construção de conhecimento favorece o lugar de pesquisatores-trabalhadores.

Cinco pesquisatores-trabalhadores foram convidados a compor a oficina de conversação coletiva a partir do diário de campo, aqui nomeado como dispositivo de conversação. Lourau (1993, p. 30) usa essa terminologia para nomear esse instrumento utilizado numa intervenção que "consiste em analisar coletivamente uma situação coletiva".

Acordamos data e horário possível para todos e cada um recebeu o dispositivo de conversação (Diário de campo) para que os pesquisadores-trabalhadores pudessem ler antes do encontro. No dia marcado acordamos a dinâmica de conversação que foi a partir daquilo que chamou atenção na leitura. O encontro foi gravado e transcrito, posteriormente elencados analisadores que se destacaram nas intervenções junto ao GTO, de acordo com os objetivos da investigação e das interrogações que surgiram durante o processo de pesquisa. Segundo Baremblitt (2002) um analisador é algo que emerge numa intervenção, como resultante de forças contraditórias que se articulam num dado campo, podendo ser um elemento "natural", quando é constitutivo do campo (uma situação espontânea, um tema que emerge em uma conversa, por exemplo) ou construído pelo analista institucional (a exibição de um filme, uma roda de conversa, uma peça teatral, etc.). A função do analisador é provocar a elucidação do que não está explícito nas relações institucionais, fazendo emergir o "não dito", os conflitos, os preconceitos, os desejos. Aqui, o que emergiu como analisadores foram temas em torno dos quais se desenvolveram as conversações e que posteriormente articularam as análises.

Cada pessoa neste estudo recebeu o nome de uma flor, sendo desta forma garantidos os preceitos éticos do anonimato. Foram também respeitados os princípios de participação voluntária, ciência dos objetivos da pesquisa, além de cuidados com a integridade dos participantes.

\section{Reflexões sobre a experiência de análise coletiva}

Com a leitura e análise do material produzido na oficina de conversação coletiva foi possível eleger alguns temas/analisadores. Na experiência com o GTO Sociedade CAPS o próprio grupo funcionou como analisador construído, ao tempo que os temas discutidos, as concepções e práticas sobre as atividades propostas e saúde mental, as discussões sobre processos de trabalho, relações de opressão e possibilidades de ruptura evidenciaram modos de funcionamento das instituições que atravessam o campo da saúde mental e da própria sociedade, foram explicitados e colocados em análise.

Foram quatro os temas/analisadores evidenciados, que discutiremos a seguir: 1. Compreensões sobre o Teatro do Oprimido na Saúde Mental; 2. Proposição teórico-prática do Teatro do Oprimido; 3. Trabalho na saúde mental; 4. A experiência com a Oficina de Conversação Coletiva.

1. Compreensões sobre o Teatro do Oprimido na Saúde Mental. Versa sobre a organização do grupo de TO. Alguns trabalhadores da saúde mental estranharam os grupos de Teatro do Oprimido serem abertos à multiplicidade de pessoas, ou seja, qualquer usuário poderia participar, desde que manifestasse o interesse em relação à proposta, sendo o mesmo, nesta condição, sujeito de escolha de como, quanto e quando participar. Entretanto, os trabalhadores indagavam sobre o Teatro do Oprimido ser favorecedor de crise nos usuários dos serviços de saúde mental.

A percepção de práticas teatrais vivenciadas num grupo aberto remete à História da Loucura na Idade Clássica, onde Foucault (1972) discute as práticas de internação como modo de controle da loucura através da disciplinarização dos corpos, justificada pela produção do discurso do saber psiquiátrico. Nesse contexto Foucault menciona como o teatro foi desaconselhado quando os médicos formulavam ou experimentavam terapêuticas para os transtornos mentais. Um expoente, Esquirol (citado por Foucault, 1972) em sua importante obra Mental Maladies: treatise on insanity, referência para a psiquiatria, aborda a questão do teatro como perigoso para as pessoas com males da mente, afirmando que as apresentações teatrais poderiam influenciar as mentes fracas. Apesar de dizer que algumas artes traziam paz e compostura para os desvios da mente, desaconselha as representações teatrais, tanto aos loucos, quanto aos convalescentes, tanto para assistirem quanto para atuarem. 
Essa questão posta desde o início da instauração do Paradigma Psiquiátrico ainda vigora na perspectiva do campo da saúde mental a partir do Paradigma Psicossocial. Neste, ainda em construção, podemos observar representações do teatro como algo perigoso, expressas pelos trabalhadores quando perpetuam a questão de que o Teatro pode levar o fraco a sucumbir, ou que leva o insano a ser objeto de comicidade por sua condição. O que se evidencia são as diferentes perspectivas caminhando juntas, ou seja, noções diferentes convivendo nesse processo de práticas em saúde, configurando um contexto complexo de luta de forças: concepções e práticas enrijecidas (instituídas) convivem com práticas abertas, propulsoras de mudança (instituintes) num mesmo espaço.

Em conversação, os pesquisatores-trabalhadores assinalaram que a facilitação de Teatro do Oprimido em Saúde Mental necessita de uma cofacilitação. Pensaram que outra especificidade dessa prática em serviços CAPS seria o vínculo com os profissionais de referência no cuidado dos usuários, sendo o termo referência associado à proposta do Projeto Terapêutico Singular, que consiste na construção compartilhada entre trabalhadores, usuário e família de um projeto de cuidado, que condiz com as possibilidades e desejos dos sujeitos envolvidos na demanda da saúde mental.

Um dos aspectos suscitados pelo trabalho com Teatro do Oprimido no serviço oferecido pelo CAPS foi pontuado no sentido de que fortaleceu o cuidado, bem como estimulou a inserção dos sujeitos em outras atividades dentro e fora do serviço, como podemos ver nas expressões abaixo:

Uns foram tocados mesmo, foram afetados por isso, eu quero continuar, isso me fez bem, como isso que ele colocou aqui: "O teatro trouxe ânimo para me expressar." E essa pessoa já estava afastada dos grupos nessa época e retornou no Teatro do Oprimido. Desde então ele começou aqui e está fazendo grupo de Arte-Terapia, Música e Movimento. E em outro processo de teatro fora. Então, como despertou, como foi importante! (Estrelícia)

Mas a partir do momento que ele (participante do GTO) diz: "ah não vou fazer TO, vou fazer teatro convencional! Isso é massa para o convívio social dele" (Chuva de Prata).

Estas pontuações colocam aspectos positivos da prática com o Teatro do Oprimido na Saúde Mental observados pelos pesquisatores-trabalhadores, como: o sentir-se estimulado a expressar-se no mundo, a dizer de si; o retorno às atividades propostas pelo CAPS; a inserção social em demais ambientes; bem como a mobilização para ingressar em atividades extra-CAPS.

2. Proposição teórico-prática do Teatro do Oprimido. Este tema/analisador agrega questões debatidas pelo grupo e que abordaram a teoria e a prática do TO. Destacamos aqui os jogos e exercícios do Teatro do Oprimido, ou seja, o manejo das técnicas do arsenal desenvolvido por Boal e a facilitação de grupos em saúde mental, especialmente dos joguexercícios.

$\mathrm{Na}$ conversação acerca do uso deste arsenal na saúde mental ressaltamos as indagações da facilitadora do GTO registradas no Diário de Campo, que abordavam como os participantes do grupo questionavam o que seria opressão, mesmo antes do planejado/esperado/desejado pela facilitadora. Um dos pesquisatores-trabalhadores considerou:

A questão da técnica. Eu vejo aqui um questionamento sobre a questão do opressor. Estou vendo que usou alguns jogos da relação do opressor e oprimido, a própria cobra de vidro tem essa relação, o ímã afetivo, o urso, então, são os jogos e técnicas que tu fez, que talvez tenha antecipado esse questionamento com eles, do que é opressor e do que é oprimido, e não focar a desmecanização do corpo, que é o balão como prolongamento do corpo, quantos "as" existem em um "a", a própria máquina de ritmos, também, tem essa questão do opressor e do oprimido. (Chuva de Prata)

Analisando essa ponderação, observa-se uma divisão entre o que seria exercícios de desmecanização do corpo e as reflexões suscitadas pelos jogos e exercícios no Teatro do Oprimido. Verificando as pontuações de Boal (1998) que compreende o ser humano como uma unidade onde corpo-mente são amalgamados, constatamos que a divisão é apenas didática. Consequentemente, considerando todo o arsenal, apesar de dividido em séries que trabalham com determinados focos, o objetivo é a desmecanização do ser humano (Boal, 1998, 2002) do que está atrelado à cristalização dos modos de ser, agir e sentir impostos pela organização social opressiva.

Contudo, todos os jogos do Teatro do Oprimido trabalham as opressões e podem suscitar questionamentos das amarras vividas no cotidiano. A questão de facilitar um grupo de TO e planejar quando será abordado o tema da opressão é uma compreensão equivocada, porque o objeto mesmo da proposta, desde o nome (Teatro do Oprimido), é questionar relações de opressão, 
produzir reflexões para iniciar um movimento de enfrentamento/superação desta.

Mas algumas questões ainda povoam a facilitação de Teatro do Oprimido, tais como: Qual melhor forma de manejo das técnicas? Existe um modo correto? Quais jogos? Todo grupo vai precisar do mesmo movimento? Isso não engessaria a própria proposta? Quais são os conhecimentos básicos do TO para os grupos em geral e, em especial, para os da saúde mental? Tem uma regra de uso de cada jogo?

Tais indagações encontram em Boal $(1998,2002)$ respostas breves. Muitas vivências foram relatadas com o uso do Teatro do Oprimido por diversos autores. Porém, especificar o uso da técnica e os modos de usá-la talvez cristalizasse a própria proposta, inviabilizando-a. Boal (1998) diz que não se pode tê-las como um manual, mas como um norteamento e cada grupo-situação-facilitação suscitará desafios e oportunidades a serem observadas e ponderadas.

Uma análise sensata acerca do Teatro do Oprimido na contemporaneidade pode ser observada no estudo de Barbosa e Ferreira (2017), que pontuam fragilidades e pontencialidades da metodologia teatral. Percebendo ponto de crise consideram cinco perspectivas: tecnização, mercantilização, instrumentalização, individualização e fetichização. Embora acentuem tais pontos críticos, que estão intimamente ligados com as questões políticas, econômicas, sociais e históricas os autores verificam que a proposta boaleana possibilita colocar em pauta conflitos e contradições da vida.

Os pesquisatores-trabalhadores na nossa experiência parecem ter compreendido a dimensão da criação, do protagonismo, da cidadania, quando pontuam em conversação coletiva:

A proposta do Teatro do Oprimido não é para formar atores, mas para formar cidadãos e que ele tenha essa compreensão, quais são os seus direitos. [...] o Teatro do Oprimido tem uma certa cobrança sim, que você tem que primeiramente entender, e se você não entende, você não está fazendo Teatro do Oprimido, então tem essa cobrança. (Chuva de Prata)

No Teatro Convencional, às vezes, o texto já está pronto, você tem que decorar. No Teatro do Oprimido não tinha isso. Eles construíram as falas deles e foi baseado no que eles acreditam mesmo, no que eles acham de verdade, ninguém foi dizer você tem que falar assim. (Estrelícia)

No Teatro do Oprimido eles têm que entender o que eles estão fazendo lá (Copo de Leite).
Especificidades da abordagem boaleana pontuadas pelo grupo estimularam a criação, a expressividade e a reflexão. Tais características a tornam peculiar com atenção aos seus pressupostos. Retomando à questão inicial acerca da condução das técnicas do Teatro do Oprimido, é importante ressaltar que a proposta prática é atrelada à teoria e, conforme Santos, (2016), sem essa compreensão descaracteriza-se como Teatro do Oprimido.

3. Trabalho na saúde mental. É o terceiro tema/ analisador e se caracteriza por significações sobre a atividade profissional. É importante aqui acentuar a fala de Lancetti e Amarante (2015) ao pensarem sobre a saúde mental como um campo profissional e uma área de conhecimento de caráter inter e transdisciplinar, além de intersetorial, que contém a complexidade do entrecruzamento de saberes, o que a torna um campo de atuação difícil e perpassado por variáveis ideológicas, políticas, questões sociais e culturais, entre outras. Atividades em grupo, problematizadas no relato de direção, levantaram indagações acerca do diagnóstico e da organização de grupos no serviço. Seria a construção de divisões/seleções que alguns profissionais constroem a partir de um diagnóstico sobre os sujeitos que vivenciam o transtorno mental grave. Como colocaram os pesquisatores-trabalhadores em conversação grupal: "Aí você leva tudo para o campo do diagnóstico. É a história, o manicômio também me atravessa e me atravessa o tempo todo. Porque aí eu digo: ela é um perigo para si e para o mundo né!?" (Copo de leite). "Eu acho que, hoje em dia, e até fica difícil colocar isso, porque não é estigmatizar, mas a condição é diferente e, hoje em dia, eu separaria sim. Tentaria separar mais." (Angélica).

Essa questão do teatro eu acho assim que não... eu não levaria em conta o diagnóstico. (...) porque eu acho que todo mundo tem essa capacidade. (...) mas um grupo, por exemplo, que são só para pessoas que têm alucinações auditivas. Então, não tem como, são só para pessoas que têm alucinação auditiva. (Estrelícia)

Nas falas dos pesquisatores-trabalhadores surge uma divergência em que dependendo da formação profissional haverá um diagnóstico ou não que os usuários recebem, o que pode produzir um caminho de inserção em atividades diferentes no serviço. $\mathrm{E}$, ainda, como acentua "Estrelícia" isso pode ser impeditivo a determinados sujeitos ingressarem em grupos com grandes especificidades. Tal fato pode estar relacionado às experimentações do campo da Saúde Mental em busca da superação dos modos que segregam, ao lado de outras 
concepções que reproduzem as limitações desses diagnósticos como coisas "dadas".

Isso reforça a análise feita acima sobre o CAPS e os trabalhadores ainda atuarem em modos que aqui denomina-se misto: atitudes manicomiais e antimanicomiais. "Copo de Leite" fala como se sente manicomial em determinadas atitudes durante o trabalho no CAPS, o que levou "Estrelícia" a abordar a necessidade constante de suporte ao trabalhador:

"São essas coisas que talvez precise das supervisões de gente que têm outras visões aqui dentro e outras atividades fora (...) para ver se essa angústia, para ver se essa questão seja melhor resolvida." (Estrelícia)

Seria necessário um suporte ao profissional que trabalha em um modelo em construção que precisa aprender/desenvolver outros modos em uma sociedade que é excludente. Apoio ao trabalhador que se aproxima de sujeitos que vivenciam o sofrimento psíquico grave, aprofundado por grande desigualdade social, como é característico dos usuários do serviço. Esse fato pode estar associado às ações dos pesquisatores-trabalhadores quando abordaram suas práticas e as perceberam como de tutela, porque ao compreenderem os usuários como vulneráveis e em risco buscam conter o sujeito no serviço. "Estrelícia" ainda fala de observar-se por vezes maternal, o que a remete à necessidade de maior atenção ao trabaIhador e às suas próprias vulnerabilidades.

Na fala de Amarante (1995, p. 25) "a relação tutelar para com o louco torna-se um dos pilares constitutivos das práticas manicomiais". Esse espaço de conflito cotidiano ficou evidente nas elaborações de "Estrelícia", que pensando sobre o modo de atenção em saúde que tem produzido, capturado pelo modo capitalístico de produção de cuidado, que é assujeitador, ela pode problematizá-lo, indagando-se. Neste sentido, "o lugar da Saúde Mental é um lugar de conflito, confronto e contradição" (Costa-Rosa et al., 2003, p.29). Pois, refere-se a um espaço em construção, um lócus de inclusão, de potencialização dos sujeitos, embora fincado em uma sociedade excludente.

4. A experiência com a Oficina de Conversação Coletiva. Nas observações acerca do momento proposto pela Conversação Coletiva algumas questões se sobressaíram. Observamos como a proposição de fazer pesquisa foi importante para colocar em análise alguns dos desafios que estão presentes na saúde mental, como o cuidado em liberdade, a superação da tutela, a busca de terapêuticas, bem como a inclusão social. Desafios e dificuldades enfrentadas pela prática de cuidado em saúde mental que se não problematizadas coletivamente ficam restritos a práticas isoladas, pouco efetivas e desestimulantes ao conjunto de trabalhadores. A conversação que foi proposta na pesquisa pode revelar necessidades, seja de supervisão clínica institucional, de educação permanente ou mesmo de que a saúde mental como campo com suas singularidades tem a peculiaridade de estar sempre necessitando de criações para uma atenção ampliada e integral.

Os trabalhadores colocam suas necessidades e percepções do que foi o momento:

"É muito gratificante pra gente, quem dera termos mais momentos assim." (Chuva de Prata).

"Experiência mesmo, conhecimento, troca de experiência. Muito bom! E reviver, porque você vai tendo outras percepções do que você tinha na época [das atividades do GTO]. Agora, olha o que aconteceu." (Estrelícia).

O conhecimento construído coletivamente proporcionou outros olhares e experiências. Demonstrando as possibilidades de favorecimento do campo da saúde de investigações que produzem análises coletivas, compartilhando saberes e fazeres.

\section{Considerações finais}

No caminho para construção de novas zonas de inteligibilidade acerca do objetivo deste estudo foram executados alguns movimentos ou trajetos. Estes foram estruturados com base nos princípios fundamentais desta investigação, ou seja, no seu caráter de análise coletiva, uma vez que o conhecimento é produzido em relação, bem como na legitimidade das construções fincadas a partir de casos singulares (aqui compreendidos não como individuais, mas como casos particulares de conversações, diálogos, relações).

Nesta pesquisa o Diário de Campo e a Oficina de Conversação Coletiva se configuraram como estratégias dialógicas para o favorecimento de significações acerca do Teatro do Oprimido na saúde mental.

Verificou-se o desenvolvimento da expressividade através dos meios estéticos proposto pelo Teatro do Oprimido como o principal fator de significação apontado por este estudo. O Teatro do Oprimido em saúde mental tem estimulado a expressividade e contribuído para o fortalecimento do Paradigma Psicossocial tanto no campo teórico-assistencial/epistemológico como no técnico-assistencial de forma direta, e de forma indireta com os campos jurídico-político e sociocultural. 
A expressividade estética que propõe a abordagem boaleana instiga uma investigação de si na relação com o outro e, nesse sentido, o sujeito pode ver-se em ação. Pode observar-se a si e ao outro e além modificar imagens, percepções e práticas.

Os participantes da pesquisa também pensam a questão do protagonismo social quando analisam as relações de poder no próprio serviço de saúde mental comunitário. Isso, por exemplo, quando as proposições do TO mobilizam os usuários a questionarem o lugar de paciente que aguarda a cura do mal que the acometeu e da atribuição de uma doença a ser tratada. Dessa forma, o Teatro do Oprimido se constitui como um instrumento de favorecimento do questionamento da alienação e assujeitamento.

A função terapêutica também é conferida ao Teatro do Oprimido pelos participantes. O falar de si, a criação estética, o convívio com os outros em espaço de construção artística, bem como a inserção social propiciada pela participação em atividades do GTO foram significadas pelos sujeitos participantes como fatores que ajudaram no tratamento de suas doenças, no sentir-se melhor na vida. Esses ainda são aspectos socioculturais que desafiam a atenção psicossocial e o próprio Teatro do Oprimido. Mesmo porque os trabalhadores afirmam que o TO atua no desenvolvimento do expressar-se no mundo, do retorno às atividades propostas pelo CAPS, na inserção social em demais ambientes, bem como a mobilização para ingressar em atividades extra-CAPS.

A experiência vivenciada nos remete a indagar: como está o diálogo entre trabalhadores e usuários acerca de objetivos e atuações nos serviços psicossociais? Como estão sendo pensados e dialogados na saúde mental os termos cura, doença e tratamento?

Evidenciou-se que a proposta artístico-política em questão, que problematiza relações assimétricas e subjugadoras, colocou em pauta questões importantes e que precisam ser dialogadas entre trabalhadores, usuários, familiares e sociedade, como por exemplo a internação involuntária, tão presente no campo da saúde mental e tão opressiva e destoante da proposição da atenção psicossocial.

Desse modo, o Teatro do Oprimido é uma proposta que discute questões políticas, a exemplo da internação involuntária que denuncia como a sociedade convencionou a relação com determinados modos de comportamento, aprisionando-os e retirando direitos. Ou seja, o Teatro do Oprimido ao produzir esse grande diálogo sobre opressões desnaturaliza questões histórico-sociais. Mas esse diálogo também é terapêutico, porque ao estranhar modos de viver e sentir podemos observá-los, analisá-los e modificá-los. Portanto, o Teatro do Oprimido atua de forma político-terapêutica, favorecendo a reflexão crítica e a desnaturalização das opressões, assim como a transformação de si e das práticas sociais.

Este estudo ressaltou a importância de problematizar as práticas de atenção à saúde em processo no Brasil, buscando fortalecer o cuidado dos sujeitos em sofrimento psíquico grave para que possam ser protagonistas na condução de suas vidas e além na construção de uma política pública de saúde que acolha a diversidade de necessidades em saúde da população, para que seja calcada em direitos humanos plenos. O Teatro do Oprimido demonstrou sua amplitude político-terapêutica de transformação e mobilização de modos cristalizados, atuando de modo micropolítico nas ações em saúde que priorizam o cuidado integral, a escuta e o acolhimento, e fortalecendo esse campo para ações futuras, para impactar também nos movimentos macropolíticos.

\section{Referências}

Amarante, P. (Coord.). (1995). Loucos Pela Vida: a trajetória da reforma psiquiátrica no Brasil (2 ${ }^{\mathrm{a}}$. ed.). Rio de Janeiro: Fiocruz.

Amarante, P. (2007). Saúde Mental e Atenção Psicossocial. Rio de Janeiro: Fiocruz.

Amarante, P., \& Costa, A. M. (2012). Diversidade cultural e saúde. Rio de Janeiro: CEBES.

Barbosa, I., \& Ferreira, F. I. (2017). Teatro do Oprimido e projeto emancipatório: mutações, fragilidades e combates. Sociedade e Estado, 32(2), 439-463. doi: 10.1590/s0102-69922017.3202008

Baremblitt, G. (2002). Compendio de análise instituconal e outras correntes. Rio de Janeiro: Rosa dos Tempos.

Boal, A. (1998). Jogos para atores e não atores (Edição revista e ampliada). Rio de Janeiro: Civilização Brasileira.

Boal, A. (2000). Hamlet e o filho do padeiro. Memórias Imaginadas. Rio de Janeiro: Record.

Boal, A. (2002). Arco-Íris do desejo. Método Boal de Teatro e Terapia. Rio de Janeiro: Civilização Brasileira.

Boal, A. (2009a). A Árvore do Teatro do Oprimido. In A. Boal (Org.), Teatro do Oprimido e outras Poéticas Políticas (9a ed., p. 17). Rio de Janeiro: Civilização Brasileira.

Boal, A. (2009b). A Estética do Oprimido: reflexões errantes sobre o pensamento do ponto de vista estético e não científico. Rio de Janeiro: Garamond.

Boal, A. (2019). Teatro do Oprimido e outras poéticas políticas. São Paulo: 34.

Centro de Teatro do Oprimido do Rio de Janeiro. (2011). Teatro do Oprimido na Saúde Mental. Metaxis: Informativo Do Centro de Teatro Do Oprimido, (7), 79. Recuperado de http://eps.otics.org/ material/entrada-outras-ofertas/artigos/metaxis-teatro-do-oprimido

Costa-Rosa, A., Luzio, C. A., \& Yasuí., S. (2003). Atenção Psicossocial: rumo a um novo paradigma em saúde mental coletiva. In $\mathrm{P}$. 
Amarante (Coord.), Arquivos de Saúde Mental e Atenção Psicossocial (pp. 13-44). Rio de Janeiro: Nau.

Foucault, M. (1972). História da loucura na idade clássica. São Paulo: Perspectiva.

Lancetti, A., \& Amarante, P. (2015). Saúde Mental e Saúde Coletiva. In G. W. Campos, J. Bonfim, M. C. Minayo, M. Akerman, M. D. Junior, \& Carvalho, Y. M. (Orgs.), Tratado de Saúde Coletiva (pp. 661-680). São Paulo: Hucitec.

Lapassade, G. (1989). Grupos, organizações e instituições. Rio de Janeiro: Francisco Alves.

Lapassade, G.(1995). Análise Institucional. Petrópolis: Vozes

Lei n. 10.216, de 6 de abril de 2001 (2001, 6 de abril). Dispõe sobre a proteção e os direitos das pessoas portadoras de transtornos mentais e redireciona o modelo assistencial em saúde mental. Diário Oficial da União, seção 1.

Lourau, R. (1993). Análise institucional e práticas de pesquisa. Rio de Janeiro: EdUERJ.

Lourau, R. (2004). Objeto e método da Análise Institucional. In S. Altoé (Org.), René Lourau: Analista Institucional em tempo integral (pp. 66-86). São Paulo: HUCITEC.

Lourau, R. (2014). A Análise Institucional (3를. ed.). Petrópolis, RJ: Vozes.

Magaldi, S. (1984). Um palco brasileiro: o arena de São Paulo. São Paulo: Brasiliense.

Ministério da Saúde (2007). Secretaria de Atenção à Saúde/DAPE. Saúde Mental no SUS: acesso ao tratamento e mudança do modelo de atenção. Relatório de Gestão 2003-2006. Recuperado de http://bvsms.saude.gov.br/bvs/publicacoes/relatorio_gestao_ saude_mental_2003-2006.pdf
Ministério da Saúde (2011). Secretaria de Atenção à Saúde. DAPES Saúde Mental no SUS: as novas fronteiras da Reforma Psiquiátrica. Relatório de Gestão 2007-2010. Brasília, DF: Autor. Recuperado de http://bvsms.saude.gov.br/bvs/publicacoes/saude_mental_fronteiras_reforma_psiquiatrica.pdf

Nunes, J. M. S., Guimarães, J. M. X., \& Sampaio, J. J. C. (2016). A produção do cuidado em saúde mental: avanços e desafios à implantação do modelo de atenção psicossocial territorial. Physis: Revista de Saúde Coletiva, 26(4), 1213-1232. doi: 10.1590/s0103-73312016000400008

Portaria de Consolidação no 3. (2017, 28 de setembro). Consolidação das normas sobre as redes do Sistema Único de Saúde. Recuperado de http://bvsms.saude.gov.br/bvs/saudelegis/ gm/2017/prc0003_03_10_2017.html.

Portaria $n^{\circ}$ 3.588. (2017, 21 de dezembro). Altera as Portarias de Consolidação no 3 e no 6 , de 28 de setembro de 2017, para dispor sobre a Rede de Atenção Psicossocial, e dá outras providências. Recuperado de http://bvsms.saude.gov.br/bvs/saudelegis/ gm/2017/prt3588_22_12_2017.html

Resolução no 466, de 12 de dezembro de 2012. (2013, 13 de junho). Aprova as diretrizes e normas regulamentadoras de pesquisas envolvendo seres humanos. Diário Oficial da União, seção 1. Brasília, DF: Conselho Nacional de Saúde.

Santos, B. (2016). Teatro do Oprimido: raízes e asas - uma teoria da práxis. Rio de Janeiro: Ibis Libris.

Spagnol, C. A. (2013). A construção de um dispositivo Socioanalítico para abordar situações de conflito em equipes de enfermagem. In S. L'abbate, L. C. Mourão, \& L. M. Pezzato (Orgs.), Análise Institucional \& Saúde Coletiva (pp. 333-353). São Paulo: Hucitec.

1. Espectatores foi um termo criado por Boal (1998) para caracterizar a situação ativa do espectador no Teatro do Oprimido que está propondo alternativas para o conflito encenado ou pensando como poderia proceder em tal situação. Essa questão é extremamente importante no Teatro do Oprimido porque faz parte de uma das três transgressões ao Teatro Tradicional feita por Boal (2009b) e são diferenciações que caracterizam sua proposição alternativa. São três transgressões: 1- a divisão entre palco e plateia; 2- entre espetáculo e vida real; e 3- entre artistas e não-artistas.

Emanuella Cajado Joca, Mestre em Saúde Coletiva pela Universidade Estadual do Ceará - UECE, Doutoranda em Psicologia pela Universidade Federal do Rio Grande do Norte- UFRN,

é Servidora Pública da Rede de Atenção Psicossocial do Município de Fortaleza/CE. Endereço para correspondência: Rua Coronel Pergentino Ferreira, 155 Ap. 1703, Bairro: Fátima, Fortaleza/Ce, Cep 60.040-470. Telefones: (85) 3226-7320 e/ou 98719-7613. Email: emanuellacajadojoca@gmail.com

Maria Teresa Nobre, Doutora e Pós-doutora em Sociologia pela Universidade Federal do Ceará - UFC, é Professora Colaboradora Voluntária do Programa de Pós-graduação em Psicologia da Universidade Federal do Rio Grande do Norte - UFRN. Email: tInobre@hotmail.com

Maria Rocineide Ferreira da Silva, Doutora em Saúde Coletiva pela Universidade Federal do Ceará - UFC, é Professora Adjunta da Universidade Estadual do Ceará - UECE. Email: rocineide.ferreira@uece.br

Recebido em 09.mar.18 Revisado em 14.out.19 Aceito em 02.dez.19 